\title{
Editorial: Watershed and Stream: The Inseparable Functional/Biogeochemical Unit
}

\author{
Clara Mendoza-Lera ${ }^{1}$, Núria Catalán ${ }^{2 *}$ and Anna Lupon ${ }^{3}$ \\ ${ }^{1}$ Institute of Environmental Sciences (iES), University of Koblenz-Landau, Landau, Germany, ${ }^{2}$ Laboratoire des Sciences du \\ Climat et de l'Environnement (LSCE), CNRS-UMR, Gif-sur-Yvette, France, ${ }^{3}$ Integrative Freshwater Ecology Group, Centre for \\ Advanced Studies of Blanes, Consejo Superior de Investigaciones Cient(CEAB-CSIC), Blanes, Spain
}

Keywords: biogeochemical cycling, scales, stream processes, riparian zone, hyporheic zone, catchment, reach

Editorial on the Research Topic

Watershed and Stream: The Inseparable Functional/Biogeochemical Unit

As stated by the small catchment concept from Bormann and Likens (1967), the watershed and the stream draining it are functionally an inseparable unit. Terrestrial processes strongly affect the structure and function of aquatic ecosystems by determining the lateral inputs of energy and nutrients to streams. Watershed topography, land cover, and vegetation, are examples of terrestrial processes affecting in-stream organic matter and nutrient processing (Buffam et al., Estévez et al., Pearce et al., Yang et al.).Watershed geology and topography can also indirectly affect biogeochemical processes at reach scale by modulating both the channel morphology and preferential groundwater flow paths (Commer-Warner et al., Khamis et al., Meredith et al., Ploum et al.). Paradoxically, terrestrial and aquatic studies often evaluate processes separately, limited within their ecosystem boundaries. Placing ecosystems in boxes is useful to gain mechanistic understanding, but limits our comprehension of watersheds functionality. The studies contributing to this Research Topic aim to re-visit the small watershed concept bringing together research that connects ecosystems and processes from a more integrative, catchment-scale approach.

In the last decades, land cover is quickly changing due to anthropogenic processes such as increasing urbanization or the abandonment of agricultural lands (Grimm et al., 2008; Seto et al., 2012). Estévez et al. shed some light on the effect of the later on stream biogeochemistry by showing that dissolved organic matter (DOM) properties in streams mostly reflected present-day gradients of riparian cover rather than historical legacies of land uses. On the other hand, Yang et al. show that the hierarchical scaling of human settlements in watersheds influences the spatial patterns of total phosphorus (Ptot) inputs and removal at the network scale. Specifically, they observed that the efficiency of Ptot removal relates inversely with stream-order, but that the magnitude of Ptot removed is higher in larger streams with higher urbanization.

In addition, there is a link between the effect of land use on stream biogeochemistry and its transfer to the food web (Pearce et al., Buffam et al.). In their work, Pearce et al. demonstrated that urban streams showed increased nutrient concentrations and variations in element stoichiometry compared to forested streams. Additionally, this nutrient enrichment had a bottom-up effect in the stoichiometry of primary consumers, yet this effect muted with increasing trophic positions. The influence of water chemistry can also be top-down, as shown by Buffam et al. Their work shows that mesoscale controls, determined by watershed management and properties, such as surficial sediment coverage, directly influence brown trout distribution. Once carbon and nutrients reach the river, there are two critical controls of stream water chemistry: the lateral exchange of water and materials between the river and riparian zone, and the vertical connectivity between surface and 
hyporheic water (Winter et al., 1998). Laterally, riparian-stream connections can affect stream biogeochemistry at different scales. At the reach scale, Ploum et al. demonstrated that preferential groundwater flow paths, namely DRIPs, act as control points for riparian vegetation and stream water chemistry. Specifically, they show that DRIPs areas are wetter than surrounding lands, which support specific vegetation species and supply organic matterrich water to streams. At larger scale, Estévez et al. showed that streams draining watersheds dominated by riparian forests had a greater abundance of $\mathrm{O}$-rich phenols and polyphenols because these ecosystems regulate DOM photodegradation in streams (by canopy cover) and terrestrial DOM inputs.

Vertically, Commer-Warner et al. and Meredith et al. show that spatial heterogeneity modulates reach-scale biogeochemical patterns by controlling water travel times and the exchange of nutrients between the water column and the streambed. Specifically, longer water residence times are linked to larger particulate organic matter storage and higher rates of respiration and methane production, while shorter residence times are linked to low nitrogen retention and high release. Thus, in addition to spatial patterns, temporal heterogeneity is also a key factor to consider. For example, the influence of lateral riparian-stream connections on stream DOM can vary in time depending on watershed hydrology (Ploum et al.). Further, Khamis et al. showed that the fate of stream DOM varies depending on the time scale considered. At seasonal scale, DOM tends to be removed as it is transported downstream, but at daily scale DOM is consumed during the day and released at night.

Overall, this Research Topic shows that watershed processes constraint biogeochemical patterns at different spatial (i.e.,

\section{REFERENCES}

Bormann, E. H., and Likens, G. E. (1967). Nutrient cycling. Science 155, 424-429. doi: 10.1126/science.155.376 1.424

Grimm, N. B., Faeth, S. H., Golubiewski, N. E., Redman, C. L., Wu, J., Bai, X., et al. (2008). Global change and the ecology of cities. Science 319, 756-760. doi: 10.1126/science.115 0195

Seto, K. C., Güneralp, B., and Hutyra, L. R. (2012). Global forecasts of urban expansion to 2030 and direct impacts on biodiversity and carbon pools. Proc. Natl. Acad. Sci. U. S. A. 109, 16083-16088. doi: 10.1073/pnas.121165 8109

Winter, T. C., Harvey, J. W., Lehn Franke, O., and Alley, W. M. (1998). Ground Water and Surface Water: A Single Resource. U.S. Geological Survey Circular (USA) 1139. from habitat to basins) and temporal (i.e., from daily to seasonal) scales and thus emerging as modulators of stream and riparian biogeochemistry. This Research Topic is timely, as we are witnessing unprecedented land use changes at a very fast speed, which effect in the biogeochemical cycling in freshwaters needs to be fully understood urgently. Thus, the aspects discussed here are of critical importance when setting up strategies for river, catchment, and fluvial network management.

\section{AUTHOR CONTRIBUTIONS}

All authors listed have made a substantial, direct, and intellectual contribution to the work and approved it for publication.

\section{FUNDING}

CM-L received support from German Research Foundation (DFG: ME5498/3-1 and ME5498/2-1). NC received funding from the European UnionŁs Horizon 2020 research and innovation program under the Marie Sklodowska-Curie grant agreement No.839709. AL was supported by the Government of Catalonia and the European Commission through the program Beatriu de Pinós (BP-2018-00082).

\section{ACKNOWLEDGMENTS}

We want to thank all the authors that contributed to this Research Topic, as well as the reviewers that ensured the high quality of the manuscripts.
Conflict of Interest: The authors declare that the research was conducted in the absence of any commercial or financial relationships that could be construed as a potential conflict of interest.

Publisher's Note: All claims expressed in this article are solely those of the authors and do not necessarily represent those of their affiliated organizations, or those of the publisher, the editors and the reviewers. Any product that may be evaluated in this article, or claim that may be made by its manufacturer, is not guaranteed or endorsed by the publisher.

Copyright (C) 2021 Mendoza-Lera, Catalán and Lupon. This is an open-access article distributed under the terms of the Creative Commons Attribution License (CC BY). The use, distribution or reproduction in other forums is permitted, provided the original author(s) and the copyright owner(s) are credited and that the original publication in this journal is cited, in accordance with accepted academic practice. No use, distribution or reproduction is permitted which does not comply with these terms. 